\title{
O reuso de águas residuais como meio de convivência com a seca no semiárido do Nordeste Brasileiro
}

\author{
Wastewater reuse as a way of living with drought in Brazil's semi-arid region
}

\author{
LUCENA $^{1}$, C, Y, S.; SANTOS ${ }^{1}$, D, J, R.; $\operatorname{SILVA}^{1}$, P, L, S.; COSTA ${ }^{1}$, E, D.; LUCENA ${ }^{2}$, R, L, . \\ yaslu13@hotmail.com;
}

\begin{abstract}
Resumo
Segundo o Atlas dos desastres naturais do Brasil, as secas e estiagens são o tipo de desastre mais recorrente no país, responsável por $54 \%$ do total de desastres registrados, sendo a região Nordeste a mais afetada. Com o problema da carência hídrica nesta região do país, torna-se fundamental utilizar a água racionalmente e priorizar formas sustentáveis para o seu reaproveitamento. Nesse contexto, este trabalho tem por objetivo principal apontar as vantagens das ações de reuso de águas de esgoto no semiárido brasileiro, destacando as práticas mais adequadas e viáveis à região, tomando por base experiências já existentes em áreas semelhantes e suas possíveis aplicações no município de São Fernando/RN. Através da pesquisa documental e de campo, pode-se afirmar que no município de São Fernando/RN, as duas ETEs, que realizam tratamento do tipo secundário e se encontram em perfeito estado de funcionamento, podem servir de fonte de água para irrigação de alimento animal bem como para arborização urbana.
\end{abstract}

\begin{abstract}
According to the Brazilian natural disasters Atlas, droughts are the most recurrent kind of disaster in the country, accounting $54 \%$ of all recorded disasters, and the Northeast region is the most affected. With the problem of water deficiency in Brazil's region, it is fundamental to use water rationally and prioritize sustainable ways to reuse it. In this context, this work has as main aim show the advantages of the wastewater reuse in the Brazilian semi-arid, highlighting the most appropriate and possible practices in the region, based on existing experiences in similar areas and their possible applications in São Fernando/RN city. Through literature and field research, it can be stated that in the São Fernando/RN city, the two TSEs, that perform secondary treatment and are working in perfect order, could serve as irrigation for animal food as well as urban afforestation.
\end{abstract}

Keywords: Brazil's semi-arid region; wastewater reuse; São Fernando/RN.

Palavras-chave: semiárido brasileiro; reuso de água de esgoto; São Fernando/RN.

\section{INTRODUÇÃO}

Sabe-se que a principal característica climática do semiárido do Nordeste brasileiro é a instabilidade temporal e espacial das chuvas associada as elevadas taxas de temperatura e evaporação. Com precipitação média anual igual ou inferior a 800 milímetros e temperaturas medias anuais elevadas, iguais e superiores a $25^{\circ} \mathrm{C}$, esse tipo climático abarca quase todo o interior do Nordeste, incluindo ampla parte do território do estado do Rio Grande do Norte - RN. O semiárido brasileiro estende-se por cerca de $900.000 \mathrm{~km}^{2}$, e em sua porção nuclear (em torno de $500.000 \mathrm{~km}^{2}$ ), a pluviometria anual é inferior a 600mm (AB’SÁBER, 1974, 1977). Segundo AB'SÁBER (1977), em outras faixas do globo, com os mesmos totais pluviométricos, tais

\footnotetext{
${ }^{\text {I} C l a r a ~ Y a s m i m ~ d e ~ S o u z a ~ L u c e n a, ~ D e p a r t a m e n t o ~ d e ~ G e o g r a f i a, ~ U n i v e r s i d a d e ~ F e d e r a l ~ d o ~ R i o ~ G r a n d e ~ d o ~ N o r t e, ~ C a i c o ́-R N, ~ B r a s i l . ~}$

${ }^{I}$ Danilla Joyce Rocha dos Santos, Departamento de Geografia, Universidade Federal do Rio Grande do Norte, Caicó-RN, Brasil.

${ }^{\text {I} P o l y a n a ~ L o r e n a ~ S a n t o s ~ d a ~ S i l v a, ~ D e p a r t a m e n t o ~ d e ~ G e o g r a f i a, ~ U n i v e r s i d a d e ~ F e d e r a l ~ d o ~ R i o ~ G r a n d e ~ d o ~ N o r t e, ~ C a i c o ́-R N, ~ B r a s i l . ~}$

${ }^{1}$ Eulália Dantas da Costa, Departamento de Geografia, Universidade Federal do Rio Grande do Norte, Caicó-RN, Brasil.

${ }^{2}$ Rebecca Luna Lucena, Departamento de Geografia, Universidade Federal do Rio Grande do Norte, Caicó-RN, Brasil.
} 
condições seriam consideradas subúmidas, não fosse a descompensação do balanço hídrico vinculada aos elevados índices térmicos regionais. Tais condições climáticas têm submetido historicamente esta região do Brasil a eventos de seca que geram a crise hídrica com inúmeras consequências negativas.

Segundo o levantamento dos desastres naturais brasileiros publicado no "Atlas Brasileiro de Desastres Naturais", as secas e estiagens são o tipo de desastre mais recorrente no país, responsável por $54 \%$ do total de desastres registrados, sendo a região Nordeste a mais afetada (CEPED/UFSC, 2013). Segundo Maffra e Mazzola (2007), no Brasil os desastres naturais tendem a estar mais relacionados aos fenômenos climáticos, potencializados pela ação humana.

A açudagem na região semiárida é de suma importância, pois os baixos índices pluviométricos fazem com que se torne necessária a construção de açudes e barragens para o armazenamento de água, que abastece milhares de pessoas. De acordo com Malvezzi (2007): “O semiárido brasileiro é hoje uma das regiões mais "açudadas" do planeta, pois são aproximadamente 70.000 açudes construídos. Os pequenos e médios açudes, com volumes compreendidos entre 10.000 e $200.000 \mathrm{~m}^{3}$, representam $80 \%$ dos corpos de água nos estados do Nordeste". Estes reservatórios de água, apesar de bastante úteis e necessários no armazenamento de água nessa região, não sustentam a demanda por água em anos consecutivos de seca, como o último período de 2010 a 2016 (MARENGO et al, 2017), visto que estão submetidos a elevadas taxas de evaporação.

Com o problema da carência hídrica, torna-se fundamental reduzir o consumo de água, utilizá-la racionalmente e priorizar formas sustentáveis para o seu reaproveitamento. É de suma importância gerenciar os recursos hídricos disponíveis, para que estes atendam às demandas, sem causar danos à saúde ambiental (DORIGON e TESSARO, 2010 apud CARVALHO, 2014). Com a intensificação dos processos de urbanização nas últimas décadas a demanda de água para irrigação e abastecimento tem aumentado significativamente, resultando em pressões cada vez maiores sobre os mananciais hídricos. A água de reuso, proveniente das Estações de Tratamentos de Esgotos ETEs, surge como alternativa sustentável reduzindo a demanda dos mananciais de água, isso, devido à substituição da água potável por uma água de qualidade inferior, que ainda assim, pode ser reutilizada de múltiplas formas.

O reuso das águas de ETEs pode trazer benefícios econômicos, sociais e ambientais para as comunidades em que essa prática é inserida, sendo uma das alternativas no combate a escassez de água numa região que apresenta taxas anuais de evaporação em média cinco vezes maiores que as de precipitação, o que gera uma condição natural de semiaridez que deve ser entendida como forma de estimular novas ideias e práticas de uso e reuso da água. No entanto, o uso consciente da água e 
o reuso ainda são incipientes no Brasil e sua regulamentação ainda é incompleta, tanto na escala nacional, quanto na estadual (SCHAER-BARBOSA et al, 2014).

De todo modo, entende-se como uma questão prioritária o reuso proveniente de ETEs, principalmente, quando se trata dos municípios do semiárido, visando uma perspectiva de crescimento e desenvolvimento local com segurança hídrica. Logo, o reuso também deve ser considerado como parte de uma atividade mais abrangente que é a educação, fazendo o uso racional e eficiente da água, o qual compreende a economia e os seus usos finais (usos múltiplos da água), que podem trazer benefícios ao próprio ecossistema, como também nas atividades humanas diante da escassez hídrica.

Nesse contexto, tem-se por objetivo principal apontar as vantagens das ações de reuso de águas de esgoto no semiárido brasileiro, destacando as práticas mais adequadas e viáveis à região, tomando por base experiências bem sucedidas já existentes em áreas semelhantes e suas possíveis aplicações no município de São Fernando/RN. Para tanto, buscou-se: levantar informações essenciais sobre as águas provenientes das ETE e suas possibilidades de reuso; compreender as tecnologias de sistemas de tratamento, citando suas etapas e processos utilizados; destacar as vantagens e limitações nas práticas de uso de água residual; realizar reconhecimento de campo no município de São Fernando/RN; e discutir com os gestores municipais sobre as principais demandas por água e possibilidades de ações de reuso.

\section{METODOLOGIA}

\subsection{Pesquisa bibliográfica sobre o tema}

Para apontar o reuso de águas residuais como meio de convivência com à seca no semiárido brasileiro, foi necessário o levantamento de informações sobre as águas residuárias, incluindo as tecnologias dos sistemas de tratamento, citando suas etapas e processos utilizados. Do mesmo modo, o conhecimento das práticas de reuso que vêm sendo executadas com êxito foram encontradas em trabalhos acadêmicos através de artigos, livros e material audiovisual.

\subsection{Escolha da área de estudo}

O estado do Rio Grande do Norte tem $91 \%$ de seu território inserido no polígono da seca. O índice pluviométrico médio anual no RN é de $\sim 800 \mathrm{~mm}$, apresentando variação mesorregional, de modo que a maior média anual é observada na mesorregião Leste, e a menor na mesorregião Central potiguar, onde está localizado o município escolhido. 
Portanto, para analisar o potencial das ações de reuso de águas residuais no semiárido brasileiro, foi escolhido o município de São Fernando no RN, pelo fato deste ser um município localizado em área de clima semiárido, por ser quase todo saneado ( 96\%) e possuir duas Estações de Tratamento de Esgoto - ETE em funcionamento, segundo dados da própria prefeitura. São Fernando fica localizado no Seridó Potiguar, a $6^{\circ} 23^{\prime}$ de latitude sul e a $37^{\circ} 11^{\prime}$ de longitude oeste, tendo como municípios vizinhos, a leste Caicó, a oeste Jardim de Piranhas, ao norte Jucurutu e ao sul Timbaúba dos Batistas (Figura 01). Localizado na fluência do rio Seridó, na microrregião do Seridó Ocidental, exibe uma altitude média de 131 metros. Sua população em 2010 era de 3.401 habitantes e sua densidade populacional de 8,41 hab./km² (IBGE, 2017).

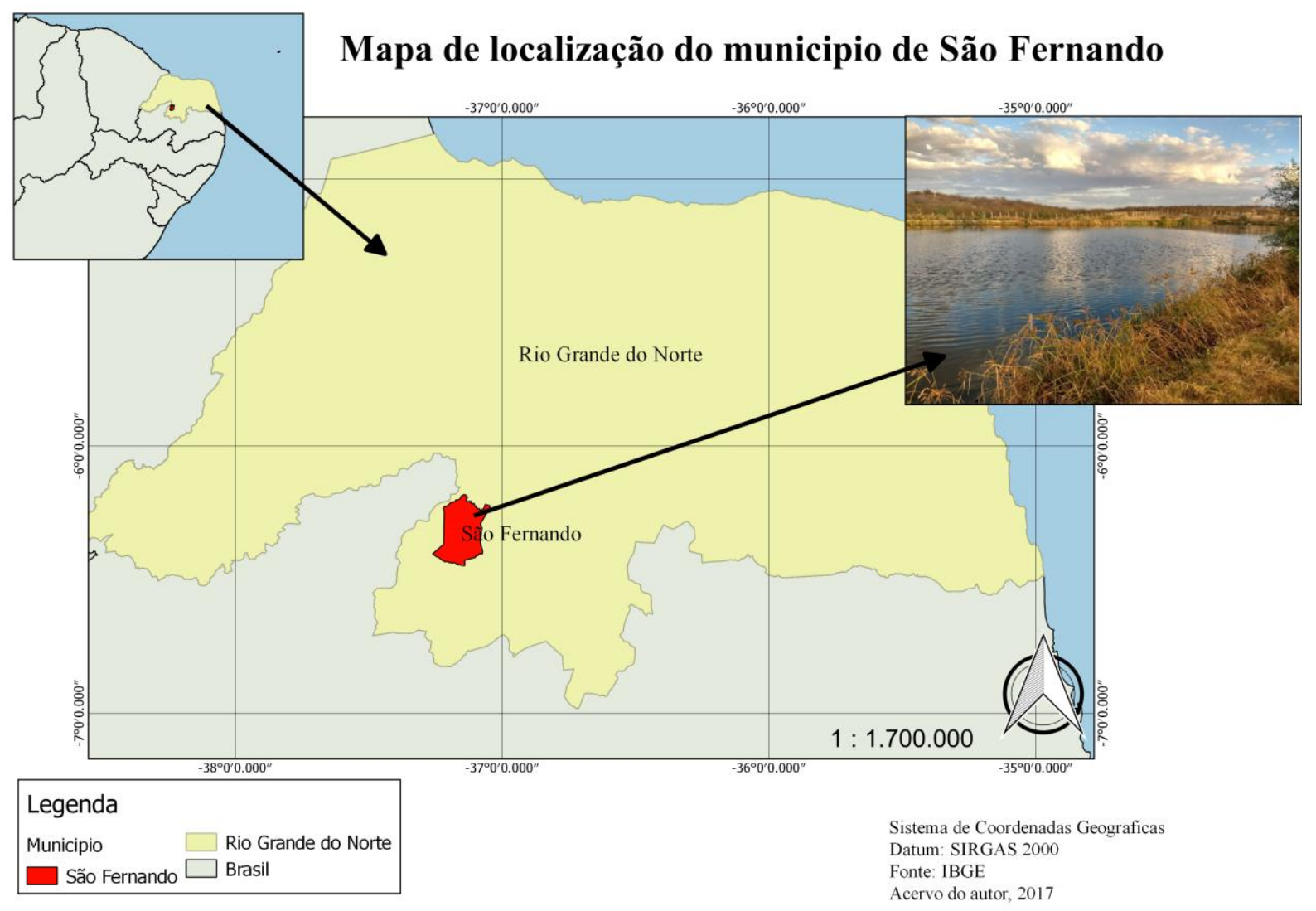

Figura 01. Mapa de localização do município de São Fernando no estado do RN e imagem da ETE 2. Fonte: IBGE e dados da pesquisa.

\subsection{Visitas técnicas e Trabalho de campo}

Visitas técnicas e trabalhos de campo foram realizados com dois objetivos: primeiramente estabelecer um contato inicial com a prefeitura de São Fernando, através do diálogo com os seus gestores, onde foram realizadas entrevistas no sentido de se obter informações sobre o saneamento básico na cidade, sobre a estrutura e o tipo de tratamento das ETE e sobre as principais demandas de água do município, havendo a possibilidade de reuso das águas residuais. Também no encontro 
com os gestores, através de seminários, mostramos as vantagens e riscos associados ao uso de águas residuárias, baseando-se no conhecimento atual e nas experiências sobre o tema. Num segundo momento, foram realizadas visitas técnicas às 2 estações de tratamento de esgoto ETE do município onde observou-se in loco as lagoas de tratamento e seu funcionamento além do reconhecimento da área do entorno e proximidades das ETE, na perspectiva de ocorrer o uso dessas águas em área rural e urbanizada. Após as visitas e trabalhos de campo, elaborou-se um check-up preliminar sobre as possibilidades de reuso das águas residuárias em São Fernando/RN, onde procurou-se apontar as reais possibilidades de uso, suas vantagens e riscos associados.

\section{RESULTADOS E DISCUSSÃO}

\section{1. Águas residuais e possibilidades de reuso}

O uso de águas residuais não é um conceito novo e tem sido praticado em todo o mundo há muitos anos. Existem relatos de sua prática na Grécia Antiga, com a disposição de esgotos e sua utilização na irrigação. No entanto, a demanda crescente por água tem feito do reuso planejado da água um tema atual e de grande importância (CETESB, 2010 apud CUNHA et al. 2011). O reaproveitamento ou reuso da água é o processo pelo qual a água, tratada ou não, é reutilizada para o mesmo ou outro fim. Segundo a Resolução no 54 de 28 de novembro de 2005, do Conselho Nacional de Recursos Hídricos - CNRH, o reuso de água constitui-se em prática de racionalização e de conservação de recursos hídricos, conforme princípios estabelecidos na Agenda 21. Tal prática reduz a descarga de poluentes em corpos receptores, conservando os recursos hídricos para o abastecimento público e outros usos mais exigentes quanto à qualidade; reduz os custos associados à poluição e contribui para a proteção do meio ambiente e da saúde pública.

A água de reuso é imprópria para o consumo, mas pode ser utilizada com diversos propósitos. A água pode ser reutilizada múltiplas vezes e para múltiplos usos, desde que seja tratada de modo a adquirir a qualidade compatível com esses usos e que a utilização seja economicamente viável, ambientalmente segura e aceita pela opinião pública. Os esgotos tratados têm um papel fundamental no planejamento e na gestão sustentável dos recursos hídricos como um substituto para o uso de águas destinadas a fins agrícolas, florestais, industriais, urbanos e ambientais. (CUNHA et al., 2011).

\footnotetext{
"Os principais resíduos poluidores das reservas hídricas são compostos por substâncias que têm características químicas orgânicas e inorgânicas. Eles originam-se de efluentes industriais, domésticos, hospitalares e agrícolas. Independente desses mananciais de água já estarem ou não contaminados, é necessário que se orientem ações no sentido de se fazer reuso com o mesmo ou outro fim. Essa reutilização pode ser direta ou indireta, decorrentes de ações planejadas ou não." (COSTA \& JUNIOR, 2005, p. 82).
} 
A reutilização da água levanta questões de segurança e de sustentável aproveitamento, incluindo o nível de tratamento que é necessário para alcançar uma determinada aplicação. As respostas dependem da aplicação pretendida da água. Este conceito deve ser comparado com seu uso pretendido e é uma parte fundamental no sistema de gestão sustentável das águas. O nível de tratamento que deve ser aplicado às águas residuais é determinado pela utilização prevista para o efluente tratado. (CARVALHO et al., 2014). Em sistema de reutilização de águas residuais tratadas, o fundamental é que a qualidade das águas seja adequada à utilização.

A reutilização da água em aplicações concretas, como a rega, no abastecimento de determinada indústria ou para irrigação, por exemplo, requer que sejam assegurados requisitos específicos, consequentes das características intrínsecas das águas residuais tratadas e dos potenciais efeitos decorrentes da sua posterior utilização na saúde pública e no ambiente (MONTE \& ALBUQUERQUE, 2010). Um esgoto tratado a ponto de ser devolvido aos rios e aquíferos é suficientemente limpo para lavagem de ruas, para a rega de parques e aplicações de cunho industrial. No lar, essa água tem uso na limpeza de vasos sanitários, rega de jardins e lavagem de carros. Essa água poderia substituir cerca de $40 \%$ da água potável consumida nas residências.

\subsection{Os sistemas de tratamento de água de esgoto}

Para que as águas provenientes de esgotos possam ser reutilizadas elas necessitam primeiro passar por um tratamento. O tratamento necessário para a recuperação de águas residuais está intimamente relacionado com as especificações de aplicação de reuso associado à qualidade de água requerida. Os sistemas de tratamento envolvem a aplicação de processos de separação de misturas do tipo sólido-líquido e, também, a desinfecção. Em alguns casos, podem-se aplicar tratamentos que envolvam uma combinação de processos físicos, químicos e biológicos (COSTA \& JUNIOR, 2005).

Segundo Adin \& Asano (1998) apud Trinidad et al. (2001), podem-se identificar vários níveis de tratamentos para as águas residuais. São eles:

- primário: através do qual se remove de 40 a $60 \%$ dos sólidos em suspensão;

- secundário: nesse tratamento se reduz a DBO em até 85\% e os sólidos em suspensão de 85 a 90\%;

- terciário: é empregado para eliminar nutrientes, mais de $99 \%$ dos sólidos em suspensão e a DBO em valores semelhantes.

Atualmente a CAERN é responsável pela coleta e pelo tratamento do esgoto no Estado, opera com um total de 60 ETE's do tipo lagoas de estabilização. Existem quatro tipos de lagoas de estabilização, a primeira é Lagoa Anaeróbia, a segunda é a Facultativa que são os tipos mais 
comuns e operam com cargas orgânicas menores que as utilizadas nas lagoas anaeróbias; a terceira é a de Maturação, caracteriza-se por pequena profundidade $(0,8$ a $2,0 \mathrm{~m})$ e possibilita a complementação de qualquer outro sistema de tratamento de esgotos, geralmente é instalada após a Lagoa Facultativa; a quarta é a Aeradas que têm como principal diferença a forma de suprimento de oxigênio, são providas de aeradores mecânicos de superfície instalados em colunas de concreto ou do tipo flutuantes e também de difusores (CAERN, 2017).

O sistema predominante de tratamento de esgoto utilizado pela Companhia (CAERN) é com lagoas de estabilização. Essas, em geral, realizam tratamento a nível secundário e são consideradas formas simples para o tratamento dos esgotos, podendo ser construídas isoladas ou em série. As principais vantagens das lagoas de estabilização são a elevada eficiência para reduzir matéria orgânica (70 a 80\%) e patogênica (> 90\%); não requer mão-de-obra especializada para operação; e apresentam baixo custo operacional.

No tratamento do tipo secundário predomina a etapa biológica onde a remoção da matéria orgânica ocorre por reações bioquímicas realizadas pelos microrganismos. Geralmente consistem de reatores do tipo lagoas de estabilização, lodo ativado, filtro biológico ou variantes. Estes reatores são normalmente constituídos por tanques (de formas variadas) com grande quantidade de microrganismos aeróbios ou anaeróbios. $O$ efluente do reator contém ainda matéria orgânica remanescente e grande quantidade de microrganismos, sendo muitas vezes necessário um tratamento terciário. A eficiência de um tratamento secundário pode chegar a 95\% ou mais, dependendo da operação da ETE. Os microrganismos sofrem posteriormente um processo de sedimentação nos designados sedimentadores (decantadores) secundários. Finalizado o tratamento secundário, as águas residuais tratadas apresentam um reduzido nível de poluição por matéria orgânica, podendo na maioria dos casos, serem admitidas no meio ambiente receptor (Figura 02).

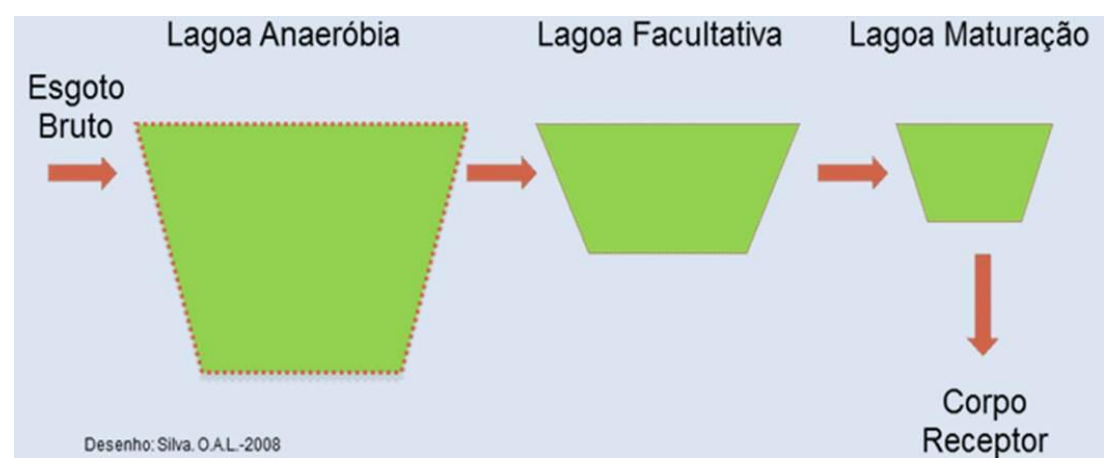

Figura 02. Esquema simplificado de uma estação de tratamento de esgoto do tipo secundário. Fonte: CAERN, 2017. 
Um esgoto tratado a ponto de ser devolvido aos rios e aquíferos pode servir como fonte perene de água para lavagem de ruas, rega de parques e aplicações de cunho industrial, irrigação e reflorestamento, como destacado anteriormente.

\subsection{As demandas por água e possibilidades de reuso em São Fernando/RN}

Na primeira visita técnica realizada ao município de São Fernando, nos encontramos com o prefeito e demais gestores municipais, onde, por meio de entrevista, nos foi passada a demanda do município no que diz respeito as principais necessidades de utilização da água, frente a carência hídrica. O município de São Fernando, assim como vários outros que fazem parte da bacia do rio Piancó-Piranhas-Açú, enfrenta um período de escassez hídrica que vem se estendendo desde o ano de 2010, com ciclos de chuvas irregulares e índices pluviométricos entre a média e abaixo da média. Essa crise hídrica, que tem base na insuficiência de água, traz prejuízos para as principais fontes de renda da região: pecuária e agricultura de milho e feijão, afetando principalmente o pequeno produtor rural que se torna obrigado a buscar outras alternativas para a irrigação das plantações e alimentação de seu rebanho. Devido a típica escassez de água que a região semiárida vem passando nos últimos anos, a Companhia de Águas e Esgotos do RN - CAERN, vem fazendo uma redução na vazão no abastecimento de água potável, que segundo dados da Prefeitura Municipal de São Fernando (2017), a CAERN está liberando água potável para toda a população em uma vazão de $138 \mathrm{~m}^{3}$ diariamente, ou seja, cada habitante tem em média, menos de 25 litros de água diários.

Isso motivou os gestores do município a buscarem novas alternativas para resolver esses problemas causados pela escassez de água, e nesse contexto, o uso das águas provenientes das ETE surge como uma viável e possível alternativa. Porém, existe uma preocupação por parte dos gestores e da população quanto a qualidade dessa água residual e se a mesma pode ser uma alternativa de uso que não traga maiores prejuízos. Desse modo, foram necessárias algumas reuniões com os gestores municipais, no sentido de compartilhar tudo o que o estado da arte aponta sobre as vantagens e riscos no uso de águas residuais, bem como sobre a remoção dos poluentes e contaminantes apontados no tratamento do esgoto do tipo secundário, o qual é realizado nas duas ETE de São Fernando/RN. Dessa forma, fomos in loco observar o funcionamento das ETE, após as reuniões na prefeitura (Figuras 03, 04 e 05). 


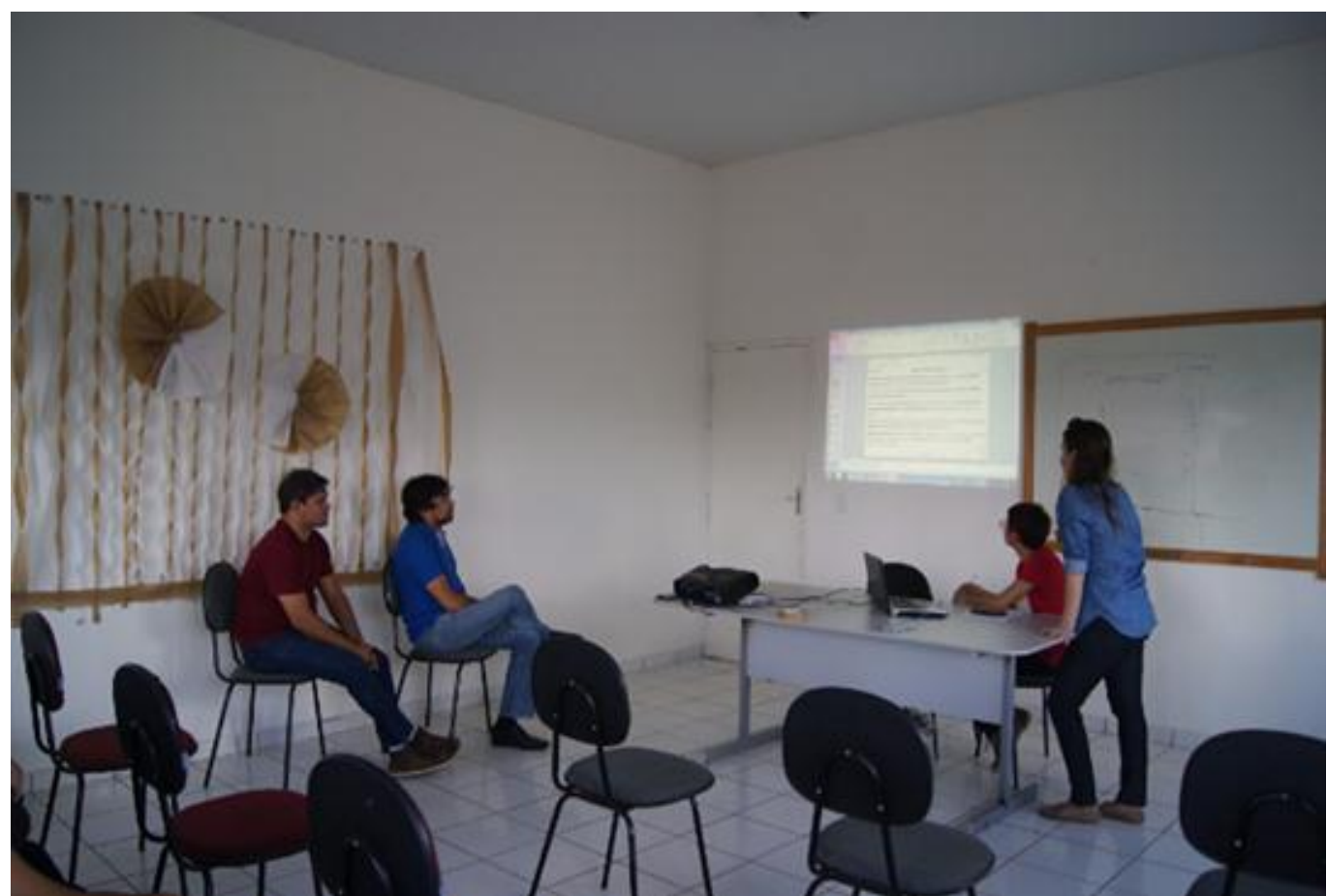

Figura 03. Reunião com os gestores onde realizaram-se entrevistas e debates sobre as possibilidades de reuso da água das ETE no município. Fonte: Dados da pesquisa, 2017.

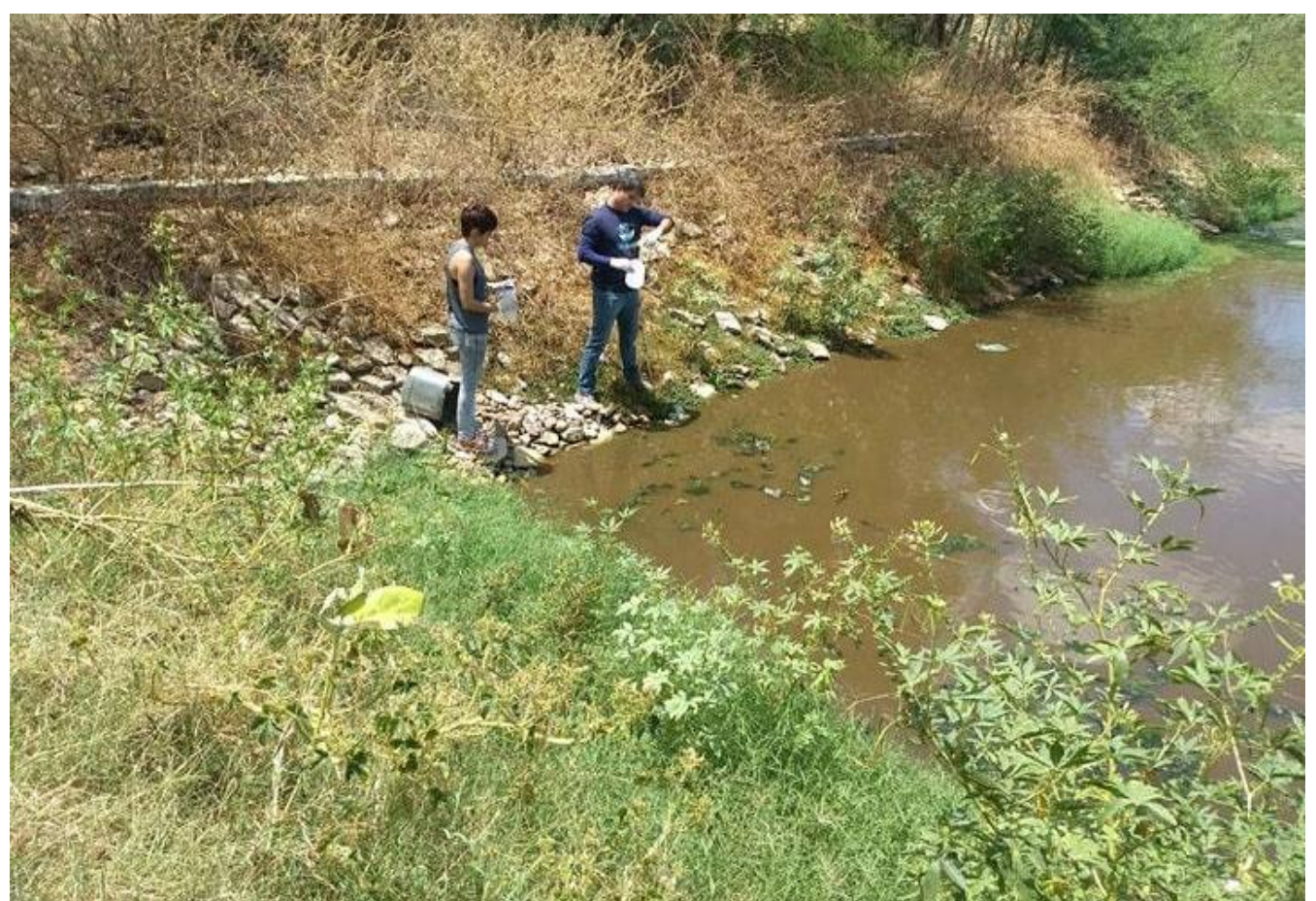

Figura 04. Visitação as ETE para observação do seu funcionamento. Fonte: Dados da pesquisa, 2017. 


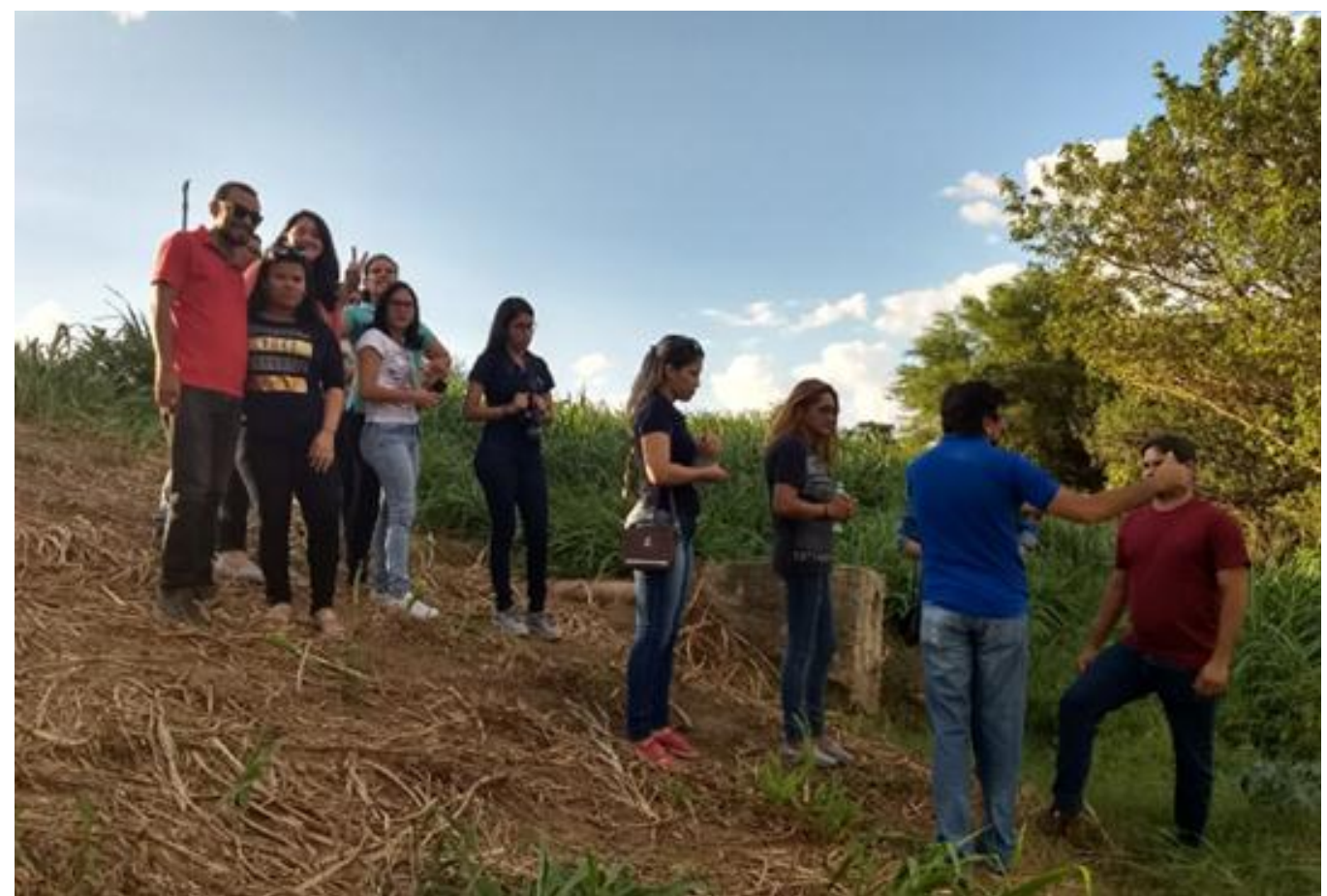

Figura 05. Visita técnica nas áreas de entorno das ETE junto aos gestores municipais. Fonte: Dados da pesquisa, 2017.

Também, durante os trabalhos de campo, visitamos as áreas que têm potencial para reuso das águas, como as áreas de potencial agrícola no entorno das ETE, onde deverão ser cultivados o capim elefante (Pennisetum purpureum Schum) para servir de alimento para o gado e eventualmente algumas espécies frutíferas como a bananeira (fig. 06) e a área de lazer do município, já em zona urbana, onde se planeja gramar e arborizar promovendo o paisagismo e um microclima mais ameno através do sombreamento oriundo da arborização (Figura 07).

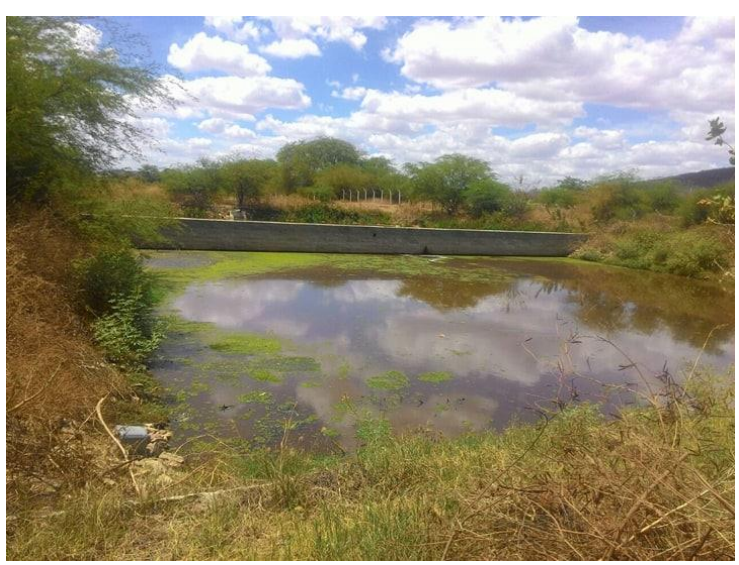

(a)

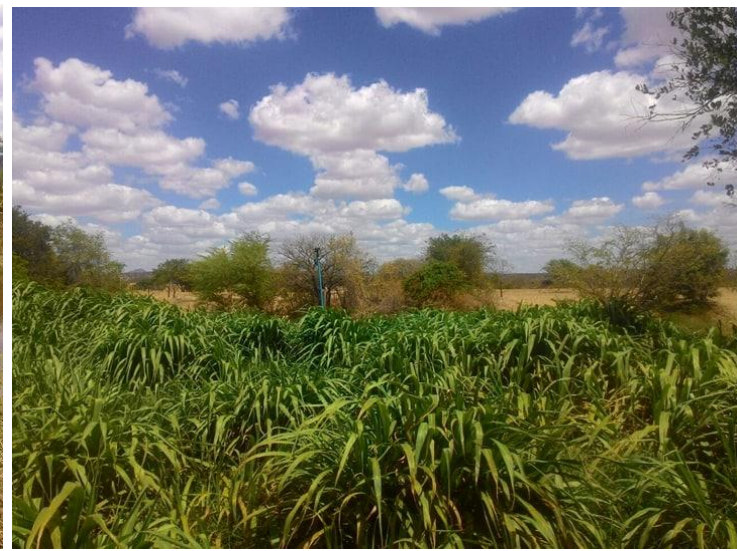

(b)

Figura $06(a)$. Área do entorno da ETE 1 onde se planeja cultivar Capim elefante e possivelmente bananeiras. Figura $06(b)$. Pequena área com plantio de capim elefante que já vem sendo realizado com água residual por um agricultor nas proximidades da ETE 1. Fonte: dados da pesquisa, 2017. 


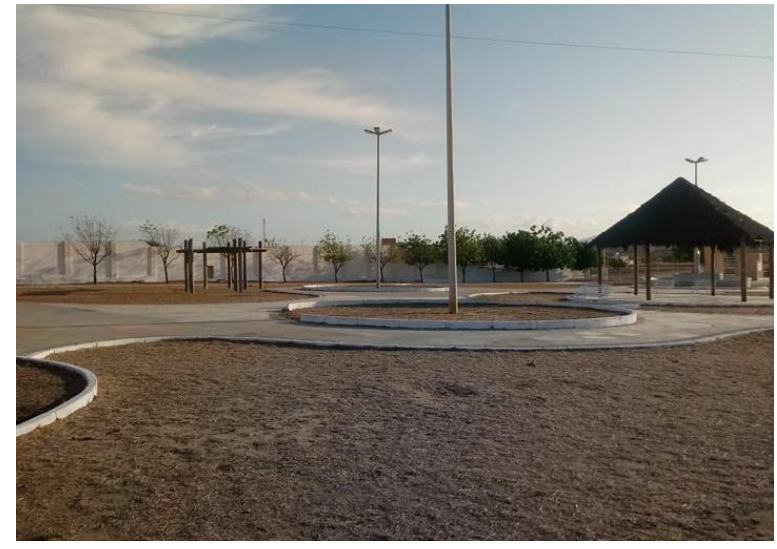

(a)

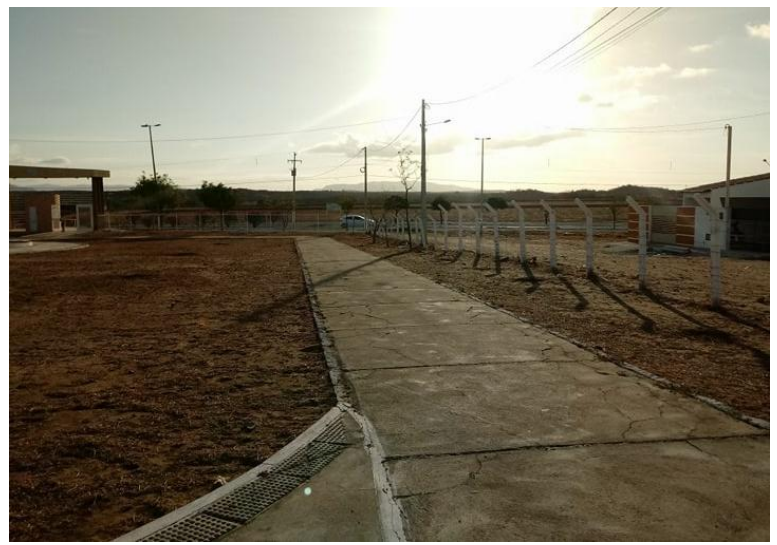

(b)

Figura 07 (a) e (b). Área de lazer no município de São Fernando próxima a ETE 2 onde pretende-se realizar a arborização urbana com água residual. Fonte: dados da pesquisa, 2017.

Cavalcante (2015), traz um estudo sobre as vantagens do uso de aguas residuais e sua aplicação na agricultura, mostrando a importância do uso dessas águas como alternativa para reduzir o uso de água potável na agricultura. Tendo como modelo a ETE da companhia de Água e Esgoto da Paraíba (CAGEPA) na cidade de Campina Grande - PB, a autora apresenta como maior vantagem do reuso a grande economia de água potável, como também o uso sustentável dos recursos hídricos, o aumento da produtividade agrícola, redução da poluição hídrica dos mananciais, o controle dos processos de desertificação, através da irrigação e dos cinturões verdes e estimulo do uso racional de águas de boa qualidade. Para Cavalcante (2015), nos projetos de reuso devem ser considerados os aspectos de saúde pública e educação ambiental, levando em consideração o planejamento de políticas e à gestão de saneamento. No município de CachoeirinhaRS o reuso da água proveniente de Estações de Tratamento de Esgoto (ETE) é uma alternativa de reutilização da água para a irrigação agrícola. Segundo, Scheer, et al. (2013). "a água de reuso apresenta potencial para fertirrigação, no entanto, as estações de tratamento devem monitorar a eficiente remoção da matéria orgânica e sólidos suspensos totais".

Isso posto, houve total acordo com os gestores do município de São Fernando sobre as reais possibilidades de implantação de práticas de reuso com as águas tratadas nas ETE 1 e 2.

\subsection{Vantagens e limitações de uso de água residuais e suas implicações em São Fernando/RN}

Os usos das águas residuais de uma maneira geral, e das domésticas, de forma particular, promove as seguintes vantagens: propicia o uso sustentável dos recursos hídricos; minimiza a 
poluição hídrica nos mananciais; estimula o uso racional de águas de boa qualidade; permite evitar a tendência de erosão do solo e controlar processos de desertificação, por meio da irrigação e fertilização de cinturões verdes; possibilita a economia de dispêndios com fertilizantes e matéria orgânica; provoca aumento da produtividade agrícola; e gera aumento da produção de alimentos (BERNARDI, 2003). Porém, as águas oriundas dos esgotos domésticos, despejadas de forma inadequada e sem tratamento e/ou removidas de modo insuficiente no processo de tratamento, ocasionam diversos problemas, muitos de grande gravidade, ambientais e de saúde pública. Os esgotos sanitários não-tratados são fontes de poluição e podem transferir patógenos para o meio aquático, tais como bactérias, vírus, protozoários e helmintos, além de compostos orgânicos, inorgânicos e minerais nutrientes.

Segundo Gerba e Smith Jr (2005), as bactérias, vírus, protozoários e helmintos são considerados os principais patógenos, presentes na aguas residuais, os quais dão origem a diversas patologias como: gastroenterite, febre tifoide, disenterias, cólera, distúrbios digestivos, dores abdominais, teníase, cisticercose, anemia, perda de peso, hepatite, meningite, pneumonia, febre, infecções respiratórias, conjuntivite, entre diversas outras. De acordo com Paganini (1997), devem haver barreiras sanitárias que precedam a contaminação, visando a proteção à saúde pública, de modo que incluam desde o tratamento de esgotos até o controle da exposição humana.

O quadro 01 representa as possibilidades de reuso de água, relacionadas aos riscos de saúde que essas águas podem causar, principalmente, se não forem manejadas de forma correta. Assim, ocorre a necessidade de discutir o reuso da água e sua relação com a saúde pública.

\begin{tabular}{|c|l|}
\hline FORMA DE REÚSO & \multicolumn{1}{|c|}{ RISCOS Á SAÚDE } \\
\hline \multirow{2}{*}{ Agrícola } & $\begin{array}{l}\text { Contaminação de consumidores de alimentos contaminados com organismos } \\
\text { patogênicos e/ou substâncias quimicas tóxicas; } \\
\text { Contaminação direta de trabalhadores } \\
\text { Contaminação do público por aerosóis } \\
\text { Contaminação de consumidores de animais que se alimentam de pastagens } \\
\text { irrigadas, ou que sejam criados em lagoas contaminadas. }\end{array}$ \\
\hline \multirow{2}{*}{ Industrial } & $\begin{array}{l}\text { Conexão cruzada entre sistemas de água potável e de reúso } \\
\text { Se utilizada como água de processo, pode haver contaminação de produtos } \\
\text { comestiveis; } \\
\text { Contaminação direta de trabalhadores }\end{array}$ \\
\hline
\end{tabular}




\begin{tabular}{|c|l|}
\hline Recreacional & $\begin{array}{l}\text { Doenças de veiculação hídrica, infeç̧ão nos olhos, ouvidos e nariz; } \\
\text { Ingestão de contaminantes químicos ou irritação dos olhos e mucosas, devido } \\
\text { aos efluentes industriais; } \\
\text { Contaminação direta de trabalhadores }\end{array}$ \\
\hline $\begin{array}{c}\text { Recarga de Aqüifero } \\
\text { peuso urbano não } \\
\text { potável }\end{array}$ & $\begin{array}{l}\text { Contaminação de aqüiferos utilizados como fonte de água potável } \\
\text { Contaminação direta de trabalhadores } \\
\text { Contado como água recuperada utilizada para irrigação de parques e jardins } \\
\text { Contaminação direta de trabalhadores }\end{array}$ \\
\hline Reúso Potável & $\begin{array}{l}\text { Ingestão de contaminantes biológicos e químicos } \\
\text { Contaminação direta de trabalhadores }\end{array}$ \\
\hline
\end{tabular}

Quadro - 1: Tipos de reuso da água e sua associação aos riscos a saúde. Fonte: Rodrigues, (2005) apud Fernandes, (2017).

Experiências de reuso de água de esgoto no semiárido do Rio Grande do Norte têm mostrado êxito, como os de Saraiva e Konig (2013), que mostraram bons resultados na utilização dessas águas na irrigação do capim elefante. Da mesma forma, como publicado no trabalho de Vale et al (2017), onde os resultados de reuso da água para irrigação de capim elefante mostraram que "o capim elefante irrigado com esgotos domésticos tratados no Campus da UFRN, no que diz respeito à questão helmintológica serve como ração animal, uma vez que não foram encontrados no capim elefante ovos dos principais helmintos que provocam doenças no gado (bovino, ovino e suíno) e parasitam o homem, que são ovos de tênia cujos hospedeiros intermediários são o gado bovino e suíno e a fascíola hepática que tem como hospedeiros os ovinos e bovinos."

Assim sendo, o município de São Fernando, através de parceria entre a prefeitura e universidade, poderá iniciar experiências com o reuso das águas, baseando-se em ações exitosas que já estão em andamento no RN e em outras cidades brasileiras, associadas à demanda municipal e aos usos possíveis e seguros das águas tratadas das ETE. Após as visitas técnicas e trabalhos de campo, concluiu-se que existe, no município de São Fernando, reais condições para a prática de reuso das águas residuárias, sendo as mais proveitosas possibilidades de reuso aquelas aplicadas ao cultivo do capim elefante e na arborização e paisagismo urbanos. Porém, tais ações devem ser feitas uns pontos estratégicos como um primeiro experimento, visto os riscos associados as águas residuárias, principalmente com relação a contaminação biológica. 


\section{CONSIDERAÇÕES FINAIS}

O município de São Fernando possui hoje uma demanda por água típica da região semiárida que vem passando por anos secos. Cada habitante tem em média, menos de 25 litros de água diários, tornando imprescindível os usos múltiplos das águas residuais para fins menos nobres que colaborem com a qualidade de vida da população e com o desenvolvimento do município.

Através da pesquisa documental e dos trabalhos de campo, pode-se afirmar que as duas ETE, do município de São Fernando/RN, que realizam tratamento do esgoto do tipo secundário, podem servir de fonte de água para irrigação de alimento animal (capim elefante) e para arborização urbana, tendo em vista a demanda municipal. Os gestores municipais se mostraram muito entusiasmados com a real possibilidade de reuso dessas águas uma vez que o município passa atualmente por uma crise hídrica fruto do desastre da seca que aflige a região Nordeste desde 2010.

Mesmo com as ETE do município de São Fernando estando em funcionamento normal, os trabalhadores e consumidores das águas residuárias devem adotar medidas de segurança indispensáveis, como por exemplo o uso de equipamentos de proteção individual e coletiva, técnicas de aplicação dos esgotos e controle da exposição humana, bem como o embasamento em padrões de qualidade sanitária das águas residuais destinadas aos diversos uso, uma vez que o reuso da água requer medidas efetivas de proteção tecnicamente e economicamente viáveis à saúde pública e ao meio ambiente.

Segundo Scheide e Tsutiya (2001), o maior desafio na utilização de águas residuais de esgoto doméstico é garantir a qualidade microbiológica e química da água de reuso. Além disso, é necessário considerar a educação ambiental pública como um importante fator no que diz respeito à utilização, conscientização e esclarecimentos da água de reuso na sua aplicação. As ações de educação ambiental que têm por finalidade educar de forma integral envolvendo aspectos físicos, biológicos, sociais, políticos, econômicos, culturais, científicos e éticos, tornam-se premissa básica para o uso racional dos bens naturais e para se obter qualidade de vida sustentável dos ecossistemas humano e natural, sendo fundamental essas ações junto à população local quando da execução do projeto de reuso de água de esgoto em São Fernando/RN, mesmo antes deste ser posto em prática.

Ações de reuso de água de esgoto tratado, como estas propostas neste trabalho para o município de São Fernando/RN, devem ser consideradas como uma técnica de convivência com a seca no semiárido brasileiro, a fim de minimizar a vulnerabilidade da população ao desastre natural que é a seca que atinge frequentemente a região semiárida do Nordeste. 


\section{REFERÊNCIAS}

AB' SABER, A. N. Problemática da desertificação e da savanização no Brasil intertropical. Geomorfologia. Universidade de São Paulo, São Paulo, 1977. 19p.

AB'SÁBER, A N. O domínio morfoclimático das Caatingas brasileiras. São Paulo, IGEOG/USP, 1974.

ASSOCIAÇÃO BRASILEIRA DE NORMAS TÉCNICAS. NBR 13.969 / 97: Tanques sépticos Unidades de tratamento complementar e disposição final dos efluentes líquidos - Projeto, construção e operação. Rio de Janeiro, 1997.

BERNARDI, C.C. Reúso de água para irrigação. Monografia (Pós-Graduação), Gestão Sustentável da Agricultura Irrigada, Fundação Getúlio Vargas, Brasília-DF, 2003.

BRASIL. Ministério do Meio Ambiente, Conselho Nacional de Recursos Hídricos. Resolução n 54, de 28 de novembro de 2005 (publicada no DOU em 09/03/2006).

CARVAlHO, N. L.; HENTZ, P.; SILVA, J. M.; BARCELlOS; A. L. Reutilização de águas residuárias. Revista do Centro do Ciências Naturais e Exatas - UFSM, Santa Maria Revista Monografias Ambientais - REMOA e-ISSN 22361308 - V. 14, N. 2 (2014): Março, p. 3164 - 3171

CAVALCANTE, K. D. B.; O uso de águas residuais e as vantagens de suas aplicações na agricultura. Universidade Estadual da Paraíba, Campina Grande-PB, 2015.

CEPED/UFSC. Atlas brasileiro de desastres naturais: 1991 a 2012 / Centro Universitário de Estudos e Pesquisas sobre Desastres. 2. ed. rev. ampl. - Florianópolis: CEPED UFSC, 2013. Volume Rio Grande do Norte. 103 p.

COMPANHIA DE ÁGUAS E ESGOTOS DO RIO GRANDE DO NORTE. Postado em: 14 Jan 2014.

Disponível em: <http://www.caern.rn.gov.br/Conteudo.asp?TRAN=ITEM\&TARG=12037\&ACT=\&PAGE=0\&PA $\mathrm{RM}=\& \mathrm{LBL}=>$. Acesso em: 13 de Outubro de 2017.

COSTA, D. M. A; JÚNIOR, A. C. B. Avaliação da necessidade do reuso de águas residuais. Natal, 2005, p. 82.

CUNHA, A. H. N.; OLIVEIRA, T. H.; FERREIRA, R. B.; MILHARDES, A. L. M.; COSTA E SILVA, S. M. A importância da reutilização de água no país. Unidade Universitária de Ciências Exatas e Tecnológicas - UnUCET - UEG. 2011. Disponível em: < https://pt.scribd.com/document/266699804/Artigo-o-Reuso-de-Agua-No-Brasil-A-Importancia-Da-

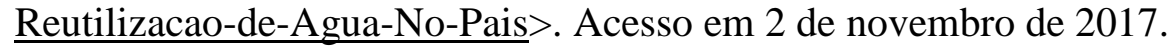

DORIGON, E. B.; TASSARO, P. Caracterização dos efluentes da lavação automotiva em postos de atividade exclusiva na região AMAI - Oeste catarinense. Unoesc \& Ciência - ACBS, Joaçaba, v. 1 n. $\quad 1, \quad$ p. 13-22, jan./jun. 2010. Disponível em https://editora.unoesc.edu.br/index.php/acbs/article/download/147/pdf_5. Acesso em: 17 de Julho de 2017.

FERNANDES, V. M. C. Padrões para reuso de águas residuárias em ambientes urbanos. Disponível em: http://cbhpf.upf.br/phocadownload/2seminario/padroesreusoaguaii.pdf Acesso em: 03/09/2017. 
GERBA, C. P.; SMITH Jr, J. E. Sources of pathogenic microorganisms and their fate during land application of wastes. Journal of Environmental Quality, 34:42-48, 2005.

INSTITUTO BRASILEIRO DE GEOGRAFIA E ESTATÍSTICA. Disponível em: <http://www.ibge.gov.br/home/geociencias/geografia/semiarido.shtm?c=4>. Acesso em: $17 \mathrm{de}$ Julho de 2017.

MAFFRA, C. MAZZOLA, M. As razões dos desastres em território brasileiro. In: Santos, R. (org.), Vulnerabilidade ambiental: desastres naturais ou fenômenos induzidos? $1^{\text {a }}$ Edição, Brasília: MMA, 2007.

MALVEZZI, R. Semi-Árido: uma visão holística. Brasília: Confea, 2007. 140p.

MARENGO, J. A.; ALVES, L. M.; ALVALA, R. C. S.; CUNHA, A. P.; BRITO, S.; MORAES, O. L. L. Climatic characteristics of the 2010-2016 drought in the semiarid Northeast Brazil region. Anais da Academia Brasileira de Ciências. Online version, p 1 - 13, 2017. DOI: 10.1590/00013765201720170206. http://www.scielo.br/scielo.php?script=sci_abstract\&pid=S0001-

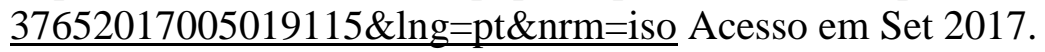

MONTE, H. M.; ALBUQUERQUE, A. Reutilização de águas residuais. Instituto Superior de Engenharia de Lisboa. Entidade Reguladora dos Serviços de Águas e Resíduos. Lisboa, Portugal. 2010.

PAGANINI, W. S. Disposição de esgotos no solo, através de escoamento à superfície, com utilização de gramíneas: avaliação do processo quanto aos aspectos sanitários. 232f. Tese (Doutorado em Saúde Pública) - Universidade de São Paulo, São Paulo, 1997.

SARAIVA, V. M.; KONIG, A. Produtividade do capim-elefante-roxo irrigado com efluente doméstico tratado no semiárido potiguar e suas utilidades. Holos. Ano 29, Vol 1, p 28 - 46, 2013.

SCHAER-BARBOSA, M.; SANTOS, M. E. P.; MEDEIROS, Y. D. P. Viabilidade do reuso de água como elemento mitigador dos efeitos da seca no semiárido da Bahia. Ambiente \& Sociedade, São Paulo v. XVII, n. 2, p. 17-32, abr.-jun. 2014.

SCHEER, G. G.; ZSCHORNACK, T.; MUNDSTOCK, C. M.; QUADROS, V.; Qualidade de água do efluente da Estação de Tratamento de Esgoto (ETE) de Cachoeirinha, RS. 2013.

SCHNEIDER, R. P.; TSUTIYA, M. T., Membranas filtrantes para o tratamento de água, esgoto e água de reuso. ABES-Associação Brasileira de Engenharia Sanitária e Ambiental, 2001. $234 \mathrm{p}$.

TRINIDAD, J. G.; GONZÁLEZ, J. A. D.; LUJAN, A. V. Recuperación y Reutilización de las Aguas Residuales en la Producción Agrícola y Pecuaria de las Zonas Áridas. Anais do XI Congreso Nacional de Irrigación. Contaminación, Tratamiento y Reuso del Agua. Guanajuato, México, 19-21 de Septiembre de 2001.

VALE, M. B.; GRILO, J. A. S.; VASCONCELOS, N. S.; FREITAS, J. P.; PEDROZA F. A. Reuso de esgotos domésticos tratados para irrigação de Capim Elefante (Pennisetum purpureum): uma abordagem parasitológica, tendo em vista sua utilização como ração animal. Disponível em: http://engemausp.submissao.com.br/17/anais/arquivos/54.pdf , Acesso em Set 2017. 


\section{AGRADECIMENTOS}

À UFRN/PROEX por conceder apoio financeiro e bolsa de extensão universitária via edital UFRN/PROEX/PROPESQ/ECT/FACISA/CERES/EMCM n ${ }^{\circ}$ 002/2017, para projetos voltados à gestão sustentável de água e energia no RN.

À Prefeitura de São Fernando/RN pelo apoio que tem dado ao desenvolvimento desse projeto.

Recebido em: 18/12/2017

Aceito para publicação em: 28/03/2018 